\title{
An assessment of perceptions, sources and uses of water among six African communities in the North West Province of South Africa
}

\author{
Hendri Coetzee ${ }^{1,3 *}$, Werner Nell ${ }^{2}$ and Carlos Bezuidenhout ${ }^{3}$ \\ 'Institutional Community Engagement Office, North-West University, Private Bag x6001, Potchefstroom, 2520, South Africa \\ ${ }^{2}$ Optentia Research Focus Area, School of Behavioural Sciences, North-West University (Vaal Triangle Campus), \\ PO Box 1174, Vanderbijlpark, 1900, South Africa \\ ${ }^{3}$ Unit for Environmental Science and Management, North-West University (Potchefstroom Campus), Private Bag X6001, Potchefstroom, 2520, South Africa
}

\begin{abstract}
The aim of this study was to assess perceptions, sources and uses of water among African residents of six different impoverished communities in the North West Province (NWP) of South Africa. A sequential exploratory mixed-methods design was used. Twenty-five purposively selected community members took part in the qualitative phase of the study, and during the quantitative phase a sample of 1000 participants was proportionately and systematically selected from the six communities. The qualitative results were used to develop a structured questionnaire to quantify and verify the initial findings. The quantitative findings revealed that the majority of participants $(72.4 \%)$ regard their water quality as average, and believe that water should be conserved and used sparingly (97.2\%) and be provided free of charge (90.5\%). Results also revealed that residents mostly obtain their water from local government (municipal) sources $(76.5 \%)$, and that they mostly use water for drinking (98\%), cooking (98.8\%), flushing toilets (95.9\%), washing themselves (bathing) (98.4\%), their hands (99\%), clothes (99.1\%), and personal property (99.3\%), as well as to water their gardens and domestic plants (93.2\%). Finally, it was found that most people (83\%) store their water in a fridge inside their homes. The results of the study have direct practical implications for water management and for the development and implementation of water-related interventions and projects in the NWP.
\end{abstract}

ABSTRACT

Keywords: African, beliefs/attitudes towards water, human-water interactions, perceptions about water, water conservation, water sources, water use

\section{INTRODUCTION}

South Africa is regarded as a country in which water is a scarce resource, which necessitates that it be used prudently. However, South Africa's Bill of Rights (section 27 (1) (b)) states that everyone has a right to sufficient, affordable and clean water for domestic use and hygienic purposes (RSA, 1996). This right is further expounded in two policy documents, the first dealing with water supply and sanitation, and the second with water (DWAF, 1994; 1996). These key documents also make special reference to the protection of South Africa's water resources, the need for community development, and the importance of water-related health and well-being. Provision and utilization of good quality water on a sustainable level is not just important to prevent disease, but also to ensure social stability (Zamxaka et al., 2004; Van Vuuren, 2013). However, in South Africa there have been an increasing number of protests linked to the delivery of basic services like water and sanitation (GCIS, 2005; Gaoganediwe, 2006; Landman, 2009; Tempelhoff, 2009). As such, residents living in poverty-stricken communities in South Africa might be facing challenges related to both the supply and quality of water. To address these issues, it is first necessary to gain a greater understanding of the perceptions, sources and uses of water that are prevalent in such poverty-stricken regions.

Human-water interaction involves the perceptions and beliefs that individuals have about water, as well as the specific behavioural and consumption practices they engage in

\footnotetext{
* To whom all correspondence should be addressed. × +27 18-852428 / +27 62704 6350; e-mail: hendri.coetzee@nwu.ac.za Received 30 June 2015; accepted in revised form 3 June 2016
}

in relation to available water resources. This phenomenon has been studied from a number of perspectives (see Hu et al., 2004; Paris, 2011), such as the sustainability of water use (Weiskel et al. 2007; Zhang and Brown, 2005), the relationship between environmental and water conservation attitudes and domestic water end use (Willis et al., 2011), and the impact that humans have on ground water (Caschetto et al., 2014; Sun and Segura, 2013). Other researchers focused on the opportunities and threats to the availability of good quality water (Adams et al., 2006) and the health risks it may pose to humans (Zamxaka et al., 2004).

The relationships between perceptions, behaviours and awareness of environmental challenges have been explored in the South African context by Anderson et al. (2007) and more recently by Wright et al. (2012). They found that a relatively small percentage of people in South Africa treat their drinking water or perceive water pollution (and quality) as a serious concern, and that perceptions of drinking water safety have remained fairly stable from 2002 to 2009 . Additionally, the General Household Survey (Stats SA, 2014) revealed that less than $10 \%$ of participants in the NWP regarded their drinking water as unsafe, and $88.4 \%$ of NWP residents have access to piped/tap water. Given the recent changes and challenges related to water in South Africa, new research is needed to establish whether these conditions have changed. Most of the abovementioned studies also do not provide in-depth understanding of the perceptions and beliefs that individuals have about water, or of their specific behavioural and consumption practices in relation to water resources available to them. Moreover, very little research has been conducted on the specific water-related beliefs and behaviours of African residents living in the NWP of South Africa, especially in impoverished communities where access to water might be problematic. Not only is the nature 
and extent of residents' water use likely to be significantly influenced by these beliefs (Russel and Fielding, 2010), but attitudes related to water have been found to vary between African and other ethnic groups in South Africa (Anderson et al., 2007). The lack of research on this population group renders it difficult to plan and develop effective policies and interventions aimed at regulating people's interactions with water in order to meet their water-related needs, whilst simultaneously ensuring their safety and sustainable and optimal use of this scarce resource. Given that the general public is recognised as an important stakeholder in relation to the management of drinking water supply (Doria, 2010) this gap in existing research is significant. Furthermore, Russel and Fielding (2010) showed that attitudes, beliefs and habits related to water play a primary causal role in water conservation, and argue that research focused on these factors could serve in promoting residential water conservation as well as informing evidence-based policy and practice. These considerations prompted the main aims of the present study, which were to assess water-related perceptions, beliefs, sources, and uses among residents of six economically impoverished African communities in the North West Province of South Africa, and to determine whether any district-level differences exist in this regard.

\section{MATERIALS AND METHODS}

\section{Design}

A sequential exploratory mixed-methods design was used in this study. In this design, findings derived from an initial qualitative research phase were used as basis for the development of a contextually relevant structured questionnaire that was administered during the subsequent quantitative phase of data collection in order to enable the initial qualitative results to be quantified and subsequently generalized. This type of design provides a more detailed and extensive understanding of a given research topic than is typically the case if either method is used in isolation, and is especially useful in cases where existing knowledge about a given topic is lacking and researchers wish to enter the research process with as few assumptions as possible (Plano-Clark and Creswell, 2007).

\section{Research context}

The study focused on 6 communities within the NWP of South Africa which has 4 district municipalities: 4 communities from Dr Kenneth Kaunda (henceforth referred to as 'Dr KK') District (Southern District) and 2 communities from Bophirima District (Western District) were included in the study (Fig. 1).

In the Dr KK district, Magopa is a small rural village to the north of Ventersdorp. Tigane is situated near the town Hartebeesfontein, Kgakala lies on the outskirts of the town of Leeudoringstad, and Lebaleng is located to the south of Wolmaransstad and close to the town Maquassi. Setshing and Tlhabologang are both large rural villages situated near Taung in the Bophirima District. Residents in all six communities speak a combination of Setswana, Afrikaans, and English. These communities can all be characterized as rural, with concomitant low levels of economic and infrastructure development and widespread poverty and unemployment. Virtually all residents in these villages are African (mainly from the Setswana cultural group) and, despite a significant degree of westernization, many still adhere (at least in some respects) to traditional Setswana cultural values. In addition to being subject to local municipal authority, residents in these communities also subject themselves to indigenous governance by local chiefs.

\section{Participants}

During the qualitative phase of the study, 25 African participants were selected by means of purposive sampling. This method

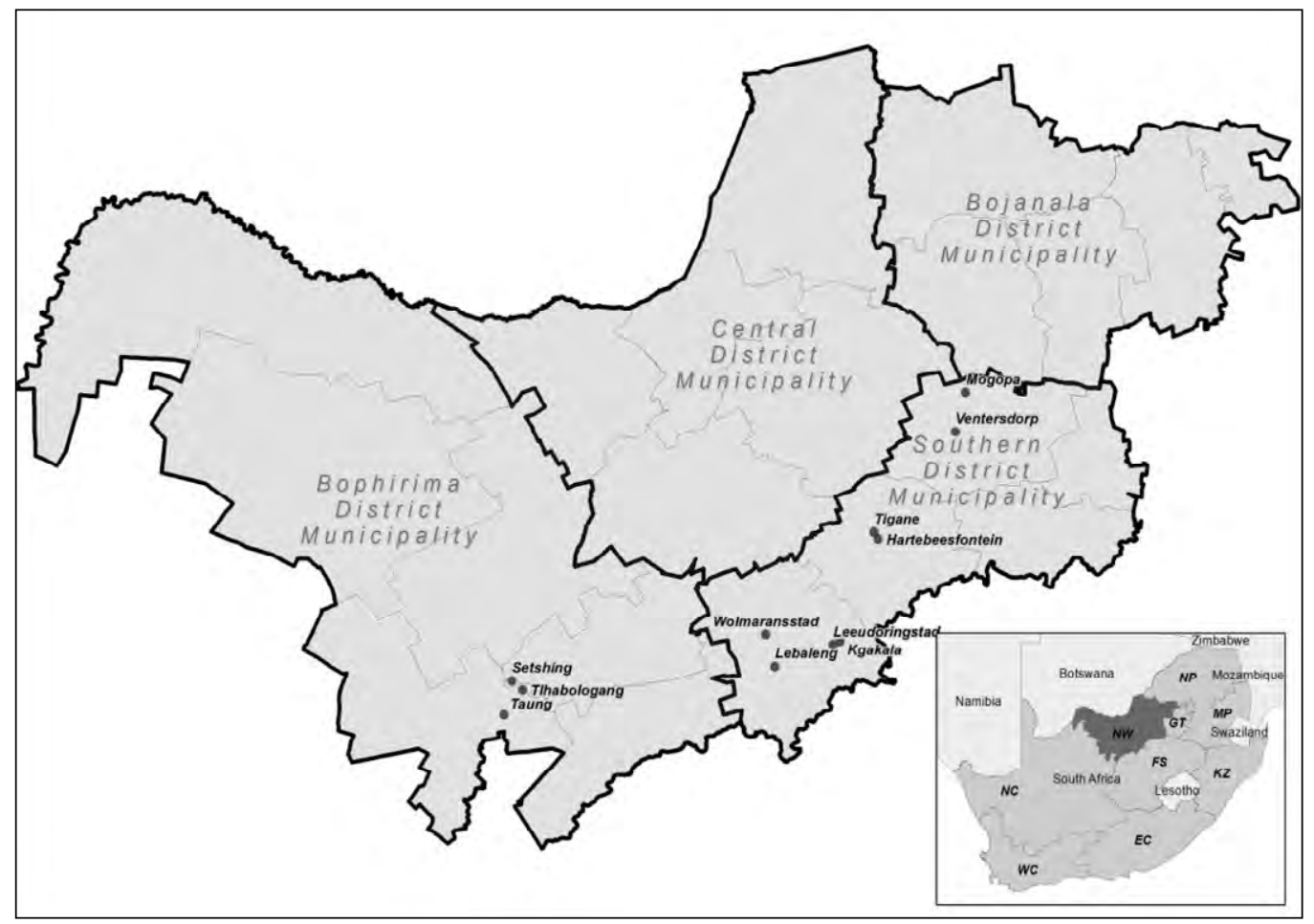

Figure 1

Locations of the six communities studied within the North West Province 
involves the selection of specific individuals who could potentially give an informed opinion about a specific research topic and who are familiar with the unique historical, socio-cultural, and political contexts in which the research is embedded (Creswell, 2008). To ensure that the participant group represented diverse spheres of communal life, the participant group included community activists, traditional leaders, political leaders (municipal ward councillors and committee members), religious leaders, educational leaders (school principals and vice-principals), youth leaders, and health practitioners (which included social workers and nurses at primary healthcare facilities). As community leaders from various spheres of life, one of these individuals' responsibilities is to hear and/or address complaints and concerns which community members have in relation to community life. As such, these leaders act as central nodes in community communication networks and are therefore highly likely to be informed about matters affecting the community, including those related to water.

During the quantitative phase, a sample of 1000 households was proportionately and systematically selected from the six different communities (according to their size). In proclaimed areas where street names and numbers were present, the sample was pre-planned by being systematically and proportionately determined according to the number of households in each community. In unproclaimed areas, the number of households was first counted, the sample proportionately allocated, and data collection then systematically conducted with a representative of each household. The profile of the participant group is outlined in Table 1.

\section{Age}

Given the possibility that water-related beliefs and utilization practices might differ between generations (e.g. traditional beliefs and practices might potentially be more prevalent among older participants than younger ones), it was considered important to record participants' ages and correlate this variable with their water-related beliefs and practices. The majority of participants (28.6\%) were aged between 41 and 50 years, while the second-largest group (24.7\%) was between the ages of 31 and 40. Smaller portions of the sample were aged between $26-30$ (14.8\%), 51-60 (13.5\%), 18-25 (8.2\%) and above 61 years (9.3\%). As such, the sample was representative of most age groups, with the exception of those under the age of 18 .

\section{Income}

As socio-economic factors have been shown to influence public perceptions of drinking water (Doria, 2010), income levels (measured in ZAR) were calculated for people who live in the same household and share at least 3 meals per week with the rest of the household. For the total group, most participants have a monthly household income ranging between R2 001 and R5 000 (32.1\%), followed by those earning R1 001-2 000 (28.8\%), R5 001-10 000 (15.5\%), R801-1 000 (8.8\%), more than R10 000 (5.6\%), R500-800 (3.5\%), R301-500 (2.1\%), R201-300 (1.6\%), R101-300 (1.1\%), and R0-100 (0.9\%).

\section{Procedure}

During the qualitative phase of the study (which took place in February/March 2013), a list with the contact details of ward councillors in each municipal area was obtained from the respective local municipal office. These ward councillors in turn

\begin{tabular}{|l|l|c|c|}
\hline \multicolumn{4}{|c|}{ TABLE 1 } \\
Characteristics of the participants ( $\boldsymbol{n}=\mathbf{1 ~ 0 0 0})$ \\
\hline Item & Options & $\mathbf{n}$ & Valid \% \\
\hline Gender & Male & 483 & 49.0 \\
& Female & 503 & 51.0 \\
\hline District & Dr Kenneth Kaunda & 427 & 42.7 \\
& Bophirima & 573 & 57.3 \\
\hline Education & None & 116 & 11.6 \\
& Primary education & 153 & 15.3 \\
& Some secondary education & 298 & 29.8 \\
& Secondary education completed & 323 & 32.3 \\
& Tertiary education & 108 & 10.9 \\
\hline Nationality & African & 1000 & 100 \\
& South African & 883 & 91.6 \\
& Other & 81 & 8.4 \\
\hline
\end{tabular}

assisted the researchers in identifying key community members who would be knowledgeable in relation to perceptions, sources and uses of water in their communities. These individuals were contacted telephonically, informed about the nature of the study, and their willingness to take part in the research was assessed. Meetings were then scheduled with consenting participants at a time and place most convenient to each participant. Once signed informed consent had been obtained, semi-structured interviews, guided by the main research questions of the study, were conducted with all participants.

During the quantitative phase (April/May 2013), local community members who met the criterion of having completed their secondary schooling were recruited as fieldworkers and trained in administering the questionnaires and conducting a community survey.

Care was taken to conduct the survey in an ethical manner and, as such, signed and informed consent was obtained from all participants once the aims, benefits and risks associated with the study were explained to them. It was also explained that participation in the study was voluntary and that respondents had the right to withdraw from the study at any time without penalty. Furthermore, once the study was completed, detailed feedback was given to the leaders of each of the six communities at a follow-up visit. During this time they were given printed copies of the research reports and the results and implications of the study were discussed with them. The possibility of follow-up research and the regular monitoring of water quality involving their communities was also discussed, to which community leaders responded favourably and enthusiastically.

\section{Data-gathering methods}

Three data-gathering methods were used during the qualitative phase, which included semi-structured interviews with key informants, focus group discussions, and observations. The findings derived from the analysis of the qualitative data were then utilized to guide the development of a structured questionnaire used to collect data during the quantitative phase of the study. This was done to ensure that the items used in the questionnaire would be reasonably valid and relevant in the particular context of the communities in which they were administered.

\section{Semi-structured interviews}

Semi-structured interviews were conducted with several participants. The benefits of using interviews as a data-gathering method are that it permits immediate follow-up questions that 
can be used for clarifications and can, thus, be regarded as a flexible mode of data collection that not only contributes to the trustworthiness of the data but also the general credibility of the study (Creswell, 2008). During the interviews participants were asked about their perceptions of the water quality in their region, about their beliefs in relation to water, the ways in which they used and stored water, and about the sources they used to obtain their water.

\section{Focus group discussions}

Small groups of between 3 and 5 participants were asked to express their opinions on a specific set of open-ended questions (noted above) regarding their community's interactions with water. Focus group discussions are generally more cost and time effective than individual interviews, and the interaction between participants often results in the sharing of information that would not occur in the context of individual interviews (Creswell, 2008). All interviews were digitally recorded and transcribed verbatim in order to ensure accuracy.

\section{Observations}

General non-participant observations and field notes (Creswell, 2008) were made in each community to supplement or support the data generated by interviews, and to ensure that the circumstances of the participants were adequately documented in order to support contextually sensitive interpretation of the findings.

\section{Structured questionnaire}

During the quantitative phase of the study, a structured questionnaire was used to gather data. The first section of the questionnaire was aimed at obtaining basic demographic information about participants' age, gender, income level, nationality, and educational level. The remainder of the questionnaire consisted of questions which were derived from the qualitative findings, and which assessed residents' interaction with water by inquiring about their perceptions of water quality in their respective communities, the ways in which they use water, the sources from which they obtain water, how they store water, and what their beliefs about water are.

\section{Data analysis}

Thematic content analysis, as outlined by Creswell (2008), was used to analyse the qualitative data. Each transcribed text was first read and studied in detail to gain a broad overview of the data. Units of meaning, including sentences or paragraphs relating to the topic, were then identified in each of the texts and coded accordingly, utilizing a manual colour-coding approach. This was followed by grouping related units of meaning under descriptive categories and themes (see Table 2). Each category and theme was then again carefully studied in detail to ascertain whether the original data truly supported the theme identified as well as to identify links with other themes.

Data from the structured questionnaires were captured by the statistical consultation services of the North-West University. Descriptive statistics were calculated for all items. Chi-square difference testing with cross tabulation and Cramer's $\mathrm{V}$ test were used to determine if there were any statistical and/or practical differences between the two districts. This method is the best suited statistical procedure to use in cases where associations or differences between independent groups need to be determined for nominal variables (Brace et al., 2012). As far as effect size and practical significance are concerned, Cramer's $V$ values of 0.10 were deemed as indicating a small difference, 0.30 a medium difference and 0.50 a large difference (Field, 2005). To compare mean scores across different groups of participants, independent $t$-tests were used. To determine the substantive size of any differences that emerged, the square root of the pooled variance (Srpv) was calculated according to the procedure outlined in Brace et al., (2012). For all the above-mentioned procedures, the cut-off point for statistical significance was set at $p<0.05$, which is the customary limit recommended when inferential statistical procedures are used in social science research (Field, 2005).

\section{RESULTS AND DISCUSSION}

\section{Findings of the qualitative phase}

During the qualitative phase of the study, 5 main themes and a number of associated categories were identified which describe participants' interaction with water. Table 2 provides an outline of these themes and categories, and illustrates each with verbatim quotes derived from the interviews.

\begin{tabular}{|c|c|c|}
\hline \multicolumn{3}{|c|}{$\begin{array}{l}\text { TABLE } 2 \\
\text { Overview of qualitative results related to human-water-interactions in the NWP of South Africa }\end{array}$} \\
\hline Themes & Categories & Verbatim example \\
\hline Perceptions about water & $\begin{array}{l}\text { Quality } \\
\text { Availability } \\
\text { Management }\end{array}$ & $\begin{array}{l}\text { 'Here in our village water is scarce, but very good. We drink it. Our } \\
\text { livestock drink it. No problem.' } \\
\text { 'Water is a scarce resource and it must be conserved.' } \\
\text { 'Sometimes we have no water, but in general there are no problems.' }\end{array}$ \\
\hline Beliefs/attitudes towards water & $\begin{array}{l}\text { Water should be free } \\
\text { Spiritual and cultural connections }\end{array}$ & $\begin{array}{l}\text { 'We all need water. Us humans and our livestock. It is government's } \\
\text { responsibility'. } \\
\text { 'Water is very important to our people (culture).' }\end{array}$ \\
\hline Sources of water & & $\begin{array}{l}\text { 'Now we are lucky. In the past we used to walk far. Now we have a } \\
\text { tap in the yard.' }\end{array}$ \\
\hline Uses of water & $\begin{array}{l}\text { Physical (physiological) needs } \\
\text { Everyday household use } \\
\text { Recreational purposes } \\
\text { Religious/spiritual and cultural purposes }\end{array}$ & $\begin{array}{l}\text { 'In our community we can fish for food and we drink the water } \\
\text { every day.' } \\
\text { 'We use it for everything, from washing to cooking and building.' } \\
\text { 'The small children swim here [pointing to a small pond] after } \\
\text { school.' } \\
\text { 'Water is very important to our people (culture). We use it to make } \\
\text { contact with our ancestors.' }\end{array}$ \\
\hline Water storage & & $\begin{array}{l}\text { 'We keep it here [under a large tree at the back of the house] in a } \\
\text { container. }\end{array}$ \\
\hline
\end{tabular}




\section{Perceptions about water}

During the interviews, participants were questioned about their perceptions of the quality and availability of water in their communities. Findings revealed that most residents understood the quality of water to relate to aspects like the clarity and colour (cleanliness and brightness), as well as smell and composition (if there are debris of plants or animal material) in their water. Perceptions of the quality of water in each community varied considerably from 'poor' to 'very good' or even 'excellent'. One of the participants from Magopa captured the general opinion of the community very well when he said: 'Here in our village water is scarce, but very good. We drink it. Our livestock drink it. No problem. This was contrasted by the sentiments of a small group of participants in the Tigane community. In the words of one participant: 'We don't like the water here. It is not good' (referring to the taste of the water).

In some of the communities in the Dr Kenneth Kaunda District, participants often commented on the availability of water, including that it is freely available compared to communities in the Bophirima District where it was often said that 'water is a scarce resource and it must be conserved.

Most participants thought that their water resources were managed effectively by local and provincial authorities. The majority of residents who were interviewed indicated that they do 'encounter problems every now and then' but, in general, they 'can't complain'.

\section{Beliefs about and/attitudes towards water}

A variety of specific beliefs about water emerged from the interviews. Chief among these was that participants often referred to water as a 'shared resource' and, as such, believed that it belongs freely to everyone, and should be available free of charge. They felt that no person should be expected to pay for water and that it is government's duty to provide people with water for drinking, sanitation, and other livelihood-supporting uses. One participant made this clear when he said: 'We all need water. Us humans and our livestock. It is government's responsibility'.

Many participants indicated that they or 'the people of our community' have a strong spiritual connection with water, which was reflected in a variety of beliefs which, in turn, generated specific types of interactions with water. Among these were the beliefs that water has the ability to cleanse not just on a physical level but also on a spiritual level, and that water can serve as means of connection with deceased ancestors. They therefore use water in rituals or ceremonial acts to cleanse themselves/others, for example, after a funeral, and/or to get in contact with their ancestors. As expressed in the words of one participant: 'Water is very important to our people (culture). We use it to make contact with our ancestors. We also use it to wash people before church or after a funeral.'

\section{Sources of water}

A number of sources of water were mentioned in each community, which included pumping water from a borehole, pit or draw-well with either a windmill or an electrical pump (motor), collecting rain water (rain harvesting), and, especially in Tigane, obtaining water from a cave or underground source, dam, fountain, pan (seasonal or permanent) or river. However, at present it appears as if residents obtain most of their water directly from a tap in the house/homestead or from a tap in their yard, or by using a communal tap for which they have to walk a distance ranging from a few to more than $100 \mathrm{~m}$ from their homesteads.
As one of the participants said: 'Now we are lucky. In the past we used to walk far. Now we have a tap in the yard.' Some communities experience occasional water shortages or lack infrastructure and therefore have to depend on water that is delivered to them by a municipal water truck.

\section{Uses of water}

Participants were also requested to explain how and for what purposes they used water. Whilst a connection exists between participants' beliefs about water and their uses of water, the former theme relates to psychological and communal attitudes and beliefs, whereas the latter focuses on concrete behavioural uses of water. Participants reported using water for a variety of reasons related to physical needs, for example to drink on a daily basis, to fish in, or to harvest plants/other edible creatures (for food). As one participant stated: 'In our community we can fish for food and we drink the water every day.' According to the participants, water was put to a variety of general uses around the household, which included using it to build their houses by using a mixture of soil and water (mud), to cook food, to flush their toilets, to wash their clothes in, to wash goods (cleaning of physical objects other that themselves), to wash themselves (bathing), or to cleanse their hands before or after eating. Outside the home, water is used to water livestock, to water crops (either small-scale subsistence gardens or larger scale farming), and to water their gardens (domestic plants). Some of these uses were captured by the words of one of the participants who stated that: 'We use it for everything, from washing to cooking and building.'

Many participants (especially the youth), use water for recreational purposes such as swimming and fishing. This appears to be more common in the rural areas, especially in Bophirima. A teacher from one of the schools confirmed this when he said that: 'The small children swim here [pointing to a small pond] after school.'

Participants' use of water for religious/spiritual and cultural purposes includes the use of water to wash either their own or other's feet before church or to wash themselves and/or others after a funeral service; the use of water to drive out or remove evil spirits from a house or homestead or even from an individual who was seen to be affected by such entities, to assist residents through periods of fasting, to initiate traditional healers in their communities, to make traditional medicine (to steam, drink or mix with other herbs), and to make traditional beer (umqhombothi).

\section{Water storage}

Participants were also asked where they stored their water. Most participants reported that once the water is obtained, it is generally either stored in a container inside the house (which was sometimes refrigerated), or is simply kept in a container outside the home.

\section{Results of the quantitative phase}

In this section, results from the quantitative phase of the study are reported, both for the group as a whole, as well as for the two districts individually. Where findings differed notably among the six communities these have also been noted.

\section{Perceptions about water}

Participants were requested to rate the quality of the water in their communities (Fig. 2). The majority (72.4\%) regarded the 
water quality in their area as 'average', with a smaller group (24.9\%) perceiving their water as being of 'good quality'. Very few participants felt that their water quality was either 'poor' $(2.5 \%)$ or 'excellent' $(0.5 \%)$. Overall, when viewed on a continuous scale, water quality is regarded as being slightly above 'average' (mean $=2.24, \mathrm{SD}=0.52)$. Comparing the mean scores across the two districts revealed that Bophirima residents regarded their water as being of better quality than Dr KK residents (mean difference $=0.24,95 \%$ CI: 0.18 to 0.31 ). An independent $t$-test confirmed that this result was statistically significant $(t=7.90$, $d f=943.31, p<0.001,2$-tailed, equality of variances not assumed) and of moderate strength (Srpv $=0.52)$. However, no statistically significant differences emerged when the perceptions of individual communities were compared.

\section{Beliefs and attitudes related towards water}

It was considered important to quantitatively assess the beliefs and attitudes that residents have about water, as such beliefs likely strongly influence, or even explain, the interactions that participants have with water, and as quantitative assessments allow for more effective generalization of findings. The nature and prevalence of these beliefs, both for the two districts and group as a whole, are graphically depicted in Fig. 3.

The two strongest beliefs and attitudes associated with water among all participants were that water should be conserved and used sparingly ( $97.2 \%$ ), and that water should be provided to residents free of charge (90.5\%). Residents also widely believed that water in their communities is being managed correctly (63.8\%). To test whether these beliefs were similarly held in both districts, multi-dimensional chi-square tests with cross tabulation were used. Whereas $71.2 \%$ of residents in the Bophirima district felt that the water sources in their community are being managed correctly, only $53.6 \%$ of those living in Dr KK district believed this to be the case: $\chi^{2}(1, N=984)=31.81, p<0.001$, a statistically significant, but fairly weak association (Cramer's $V=0.18$ ). Even more significant differences emerged when these results were compared across communities, as $87.2 \%$ of Tlhabologang residents, $80.4 \%$ of Lebaleng residents, $73.4 \%$ of Kgakala residents, $64.9 \%$ of Tigane residents, $60.2 \%$ of Mogopa residents, and only $33.2 \%$ of Setshing residents regarded their water as being wellmanaged. This suggests that concerns about water management in the Dr KK district were mostly limited to those residing in Setshing. Comparative analyses of the data according to community revealed no significant demographic or other factors that could account for these differences, suggesting that this might be a fruitful avenue for future research.

As far as cultural and religious beliefs related to water are concerned, slightly less than half of the participant group believed that they have a spiritual connection with water (45.2\%), and that they are able to establish contact with their ancestors through water (44.8\%). A small difference (Cramer's $\mathrm{V}=0.18$ ) emerged in relation to residents' belief that they have a spiritual connection with water, which was affirmed by $52.6 \%$ of Bophirima residents, but only by $35 \%$ of Dr KK residents $\left(\chi^{2}(1, N=984)=30.19, p<0.001\right)$. In a similar vein, more Bophirima (51.7\%) than Dr KK residents (35.2\%) believed that they can get in contact with their ancestors through water: $\chi^{2}(1, N=984)=26.25, p<0.001$; Cramer's $V=0.16$. In particular, beliefs related to spiritual connection and ancestor contact were particularly uncommon in Thabologang (19.7\% in both cases) when compared to all other communities, suggesting that traditional cultural beliefs might be less prevalent in this community. Overall, $74.6 \%$ of the participants believed that they

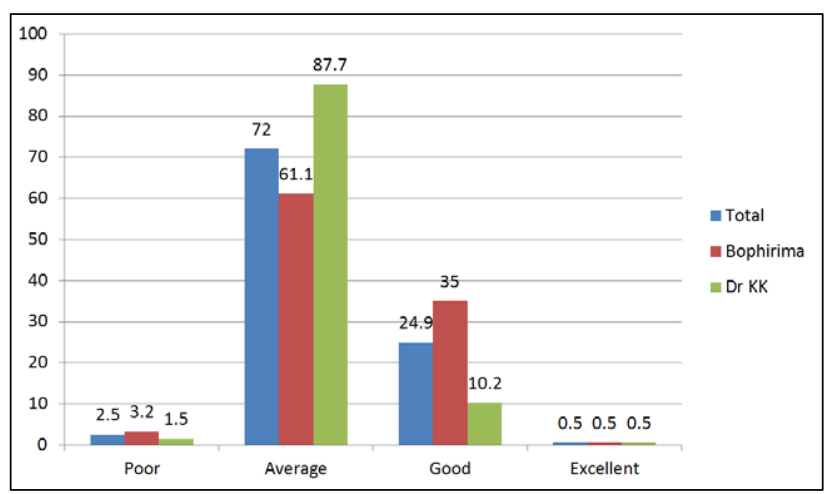

Figure 2

Perceptions about water quality in the Dr KK and Bophirima districts of the North West Province

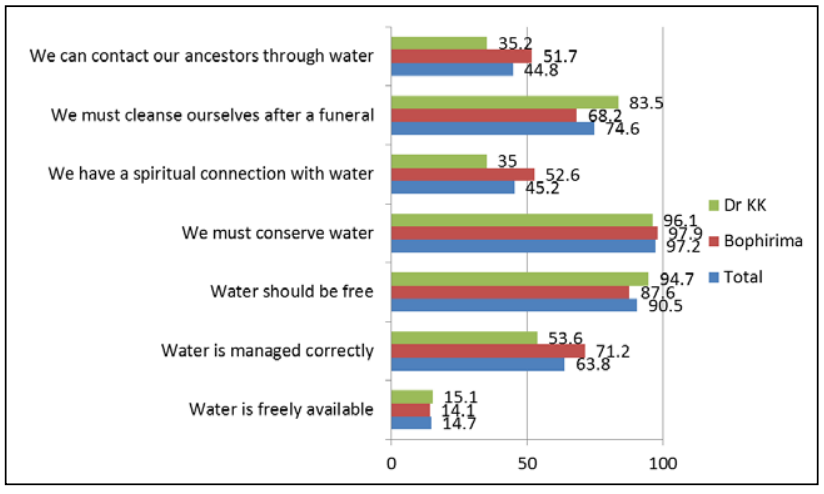

Figure 3

Beliefs and attitudes related to water in the Dr KK and Bophirima districts of the North West Province

should use water to cleanse themselves and others after a funeral. Dr KK residents were more likely to believe this (83.5\%) than those living in Bophirima (68.2\%), as confirmed by a chi-square test: $\chi^{2}(1, N=984)=29.62, p<0.001$; Cramer's V $\left.=0.17\right)$. Only a small number of the residents in each of the two districts felt that water was freely available in their communities (14.7\%), suggesting that water is considered to be a scarce resource by the majority (85.3\%) of participants in both districts. However, when these beliefs are compared across the six different communities that were surveyed, great differences emerge. In Kgakala, only $2.1 \%$ of residents believed that water was freely available in their communities; $4.5 \%$ did so in Tlhabologang, $4.8 \%$ in Lebaleng, $12.0 \%$ in Mogopa, $21.6 \%$ in Setshing, and $42.9 \%$ in Tigane. These findings suggest that free availability of water in especially the first five mentioned communities might be problematic, or alternatively that these community members' awareness of freely available water sources might be limited, in which case a need is implied for local municipalities to facilitate greater awareness in this regard.

The age and gender of participants were found to be uncorrelated with any of the beliefs and attitudes related to water that have been discussed in this section.

\section{Sources of water}

As can be seen in Fig. 4, it is clear that the majority of households obtain their water from municipal sources such as household or communal taps (76.5\%). However, a small (Cramer's V $=0.19$ ) but statistically significant difference emerged between the communities in this regard, with $83.3 \%$ of Bophirima residents 
and only $67.3 \%$ of Dr KK residents obtaining their water from this source $\left(\chi^{2}(1, N=984)=34.21, p<0.001\right)$. Analysed according to community level, more than $95 \%$ of residents in Tigane, Lebaleng, Magopa and Tlhabologang made use of a municipal water source, whereas only $40.3 \%$ of Kgakala residents and $49.4 \%$ of Setshing residents had access to this source, suggesting that access to municipal water in the latter two communities might be problematic.

Residents were asked how they typically obtained municipal water (see Fig. 5). The majority (97.9\%) sourced their water from a tap in their yards, with a smaller number of participants (45.4\%) accessing water directly through taps inside their homes. Bophirima residents appeared to have greater access to water from in-house taps than Dr KK residents (51.1\% versus 37.5\%): $\chi^{2}(1, N=978)=17.62, p<0.001 ;$ Cramer's $V=0.13$. Very few participants needed to obtain water from communal taps close to home $(3.7 \%)$, from taps or other sources that were far away from their homes $(2.1 \%)$, or from water that was delivered to the community by means of water tanks or trucks (1.9\%). However, in all three cases Bophirima residents were more likely to use these sources than those residing in Dr KK district.

Rainwater (20.6\%) (mainly in Lebaleng (33.9\%) and Setshing $(31.2 \%)$ ), and water from boreholes powered by windmills

(21.2\%) were the next most frequently exploited sources of water. Whilst $27.9 \%$ of Dr KK residents obtained their water from windmill-driven boreholes, only $16.3 \%$ of Bophirima residents did so: $\chi^{2}(1, N=989)=19.15, p<0.001 ;$ Cramer's $V=0.14$. However, significant differences existed between communities in this regard, with $41.8 \%$ of Setshing residents and $35.7 \%$ of Kgakala residents using this source, compared to less than $7 \%$ in all other communities except Tigane (22.2\%).

A variety of other minor sources of water were used by some residents, which included boreholes with electric pumps (9.6\%, mostly in Kgakala (22.1\%) and Tigane (18.5\%)), seasonal or permanent pans $(6.3 \%$, mainly in Tigane $(30.4 \%))$, dams $(4.4 \%$, mainly in Tigane $(21.5 \%)$ ), fountains $(4.5 \%$, mainly in Tigane $(21.5 \%)$ ), rivers $(4.5 \%$, mainly Tigane $(21.5 \%))$, caves or other underground sources (4\%, with only Tigane residents (19.3\%) making significant use of this source), and wells (3.8\%, mainly in Tigane (18.5\%)). As such, Tigane residents were far more likely than residents of all other communities to obtain their water from natural sources such as dams, fountains, seasonal or permanent pans and rivers. This implies that residents from this community might be more exposed to contaminants and disease agents that might occur in such water sources than members of other communities.

Participants were asked to indicate the various purposes for which they made use of water (Fig. 6). The vast majority of participants (from both districts and all communities) used water for drinking (98\%) cooking (98.8\%), washing themselves (98.4\%), their hands (99\%), clothes (99.1\%), and personal property (99.3\%), and also for watering their gardens and domestic plants (93.2\%), and for flushing toilets (95.9\%).

The only significant correlation that emerged between water usage and age and gender was that older residents were slightly more likely to use water for watering their gardens $(r=-0.11$, $p<0.001)$. About two-thirds of participants $(68.5 \%)$ used water for internal cleansing purposes (enemas), with those living in Bophirima being more likely to do so than those residing in Dr KK district $\left(85.8 \%\right.$ versus $44.7 \%: \chi^{2}(1, N=982)=187.59$, $p<0.001$; Cramer's V $=0.44$ ). Residents of Tlhabologang were far less likely than those of all other communities to engage in this practice (19.9\%). Water was also commonly used for building houses and other physical structures (94.2\%).

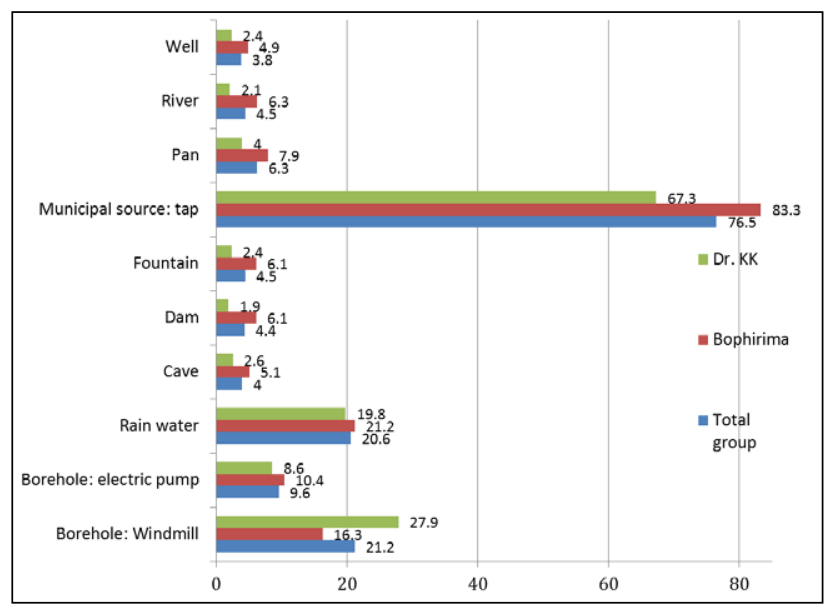

Figure 4

Sources of water for residents in the Dr KK and Bophirima districts of the North West Province

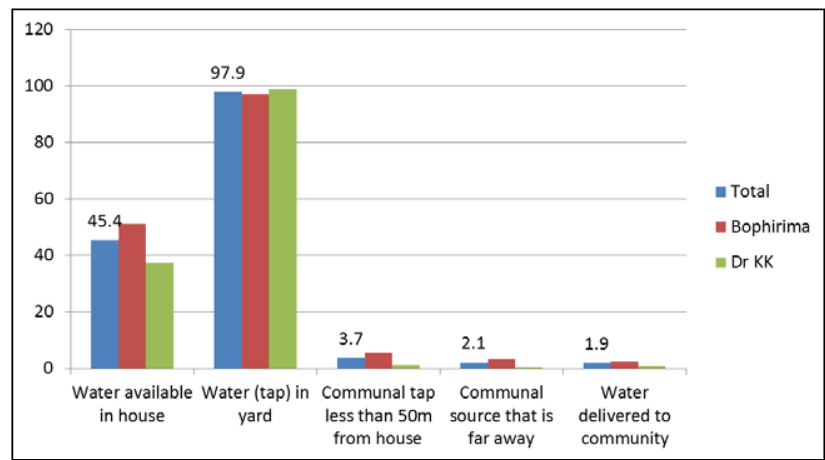

Figure 5

Municipal water sources in the Dr KK and Bophirima districts of the North West Province

In both districts, water was used in support of subsistence practices such as being given to livestock to drink $(47 \%, 56.6 \%$ in Bophirima, 33.7\% in Dr KK: $\chi^{2}(1, N=983)=50.07, p<0.001$; Cramer's $\mathrm{V}=0.23$ ), watering crops (in larger-scale farming) (27.9\%), and small-scale subsistence gardens (69.8\%), especially in the Dr KK district $\left(87.9 \%\right.$ versus $56.4 \%: \chi^{2}(1, N=990)=$ $113.69, p<0.001$; Cramer's $V=0.34)$. Whereas virtually all participants in Lebaleng (99.5\%) used water to provide to livestock for drinking purposes, only a small number of those living in Tlhabologang (9.6\%) and Mogopa (10.2\%) did so. A similar pattern emerged in relation to watering crops (large-scale farming), as only $3.2 \%$ of Tlhabologang residents and $11.4 \%$ of Mogopa residents used water for this purpose.

Water was used frequently in both districts in cultural and/or religious practices such as washing feet before church (97.1\%), assisting participants during times of fasting (91.7\%), initiating traditional healers in the community $(75.9 \%)$, and making traditional beer $(88.1 \%)$. Water also played an important role in the making of traditional medicine (67.4\%), especially in the Bophirima district $(78.6 \%$, versus $52.1 \%$ in Dr KK district: $\chi^{2}(1, N=982)=76.50, p<0.001$; Cramer's $\mathrm{V}=0.28)$. This use was very prevalent in Lebaleng (99.5\%), but relatively uncommon in Thabologang $(26.7 \%)$. Another difference in the cultural use of water was that Bophirima residents were more likely to use water to wash themselves and others after a funeral $(72.5 \%)$ than participants residing in the Dr KK district $(50 \%): \chi^{2}(1, N=992)=52.40$, $p<0.001$; Cramer's $\mathrm{V}=0.23$. However, when considered 
from a community perspective, this practice was more or less equally common in most communities except for Tlhabologang, where only $27.4 \%$ of the participants used water for this purpose.

The final cultural use that was identified was that $61.4 \%$ of residents used water to drive out or remove evil spirits, though this practice was far more common in Bophirima district (75\%) than it was in Dr KK district (42.7\%): $\chi^{2}(1, N=983)=104.99, p<0.001$; Cramer's $V=0.33$. More specifically, $100 \%$ of Lebaleng residents, but only $18.7 \%$ of those living in Tlhabologang, engaged in this ritual.

Lesser uses of water that occurred with more or less similar frequency in communities of both districts included watering (subsistence) crops (27.9\%), and using water to obtain food such as fish and other aquatic food sources (30.7\%). However, the latter use was fairly rare in Tlhabologang (4.5\%) and Mogopa (8.5\%).

Finally, water was used for recreational activities such as fishing and swimming in both districts (63.5\%), especially in Lebaleng (95.7\%).

\section{Water storage}

The majority of participants from both districts (83\%) store their water in a fridge inside the home (Fig. 7). Results were highly similar across all six communities. Almost two-thirds of residents (64.5\%) also made use of unrefrigerated containers inside the house to store their water $(82.8 \%$ of Tlhabologang residents, and only $46.2 \%$ of Setshing residents). Finally, $47.8 \%$ of participants stored water in containers outside their homes. However, great differences occurred among communities in this regard (Tlhabologang 15.9\%; Mogopa 23.4\%; Tigane 34.1\%; Setshing 51.0\%; Kgakala 62.6\%; Lebaleng 83.8\%).

\section{CONCLUSIONS AND IMPLICATIONS FOR WATER MANAGEMENT}

The aim of this study was to assess perceptions, sources and uses of water among African residents of 6 different relatively impoverished communities in 2 districts of the NWP of South Africa by means of a sequential exploratory mixed-methods

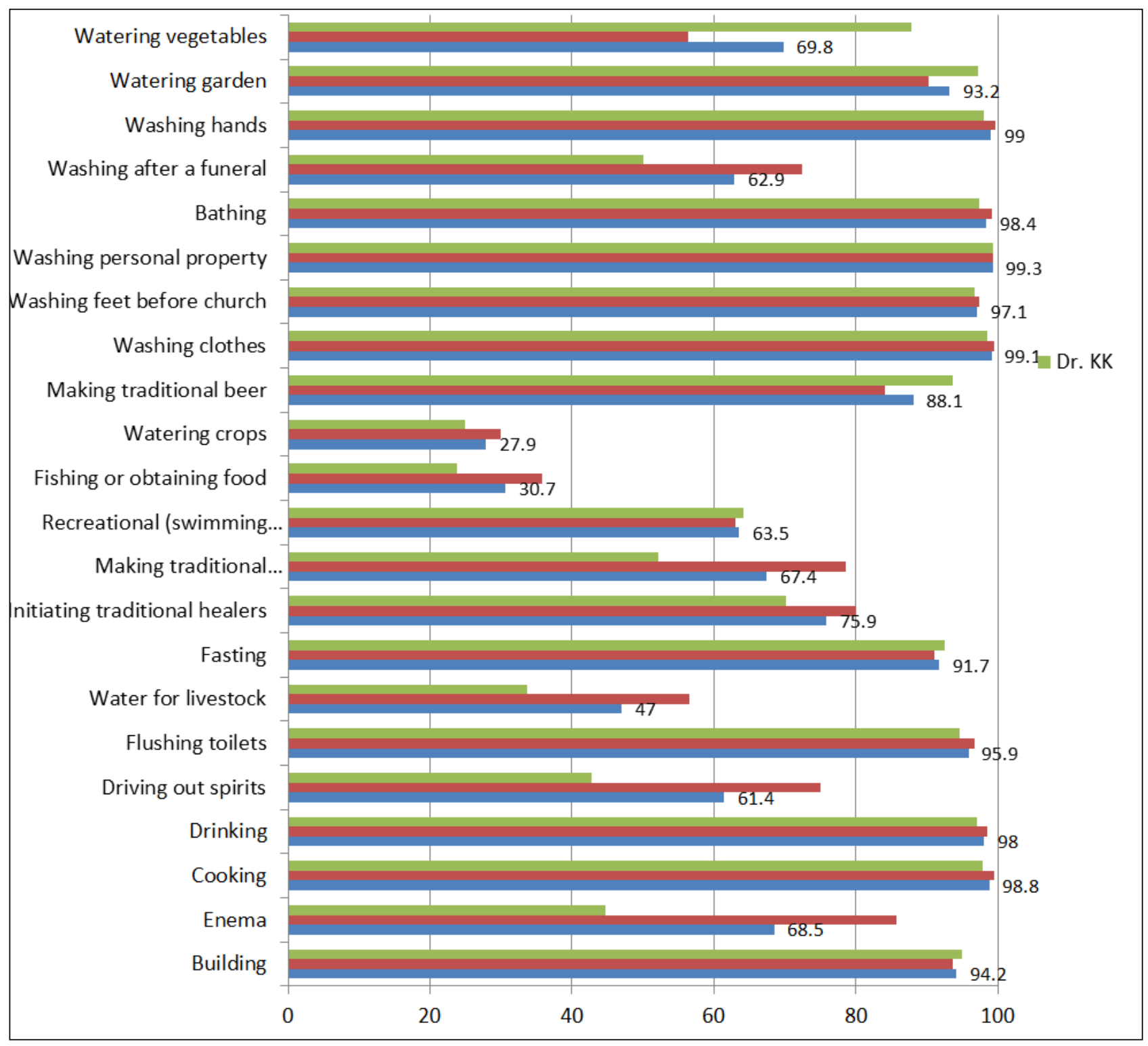

Figure 6

Uses of water in the Dr KK and Bophirima districts of the North West Province 
design. Overall, the findings revealed that virtually all residents believed that water is a scarce resource that should be conserved, and that water should be provided free of charge to all citizens by the government. Participants regarded the quality of water in their communities as being average to slightly above average, with Bophirima residents regarding their water as being of better quality than Dr KK residents. This is echoed by findings from the General Household Survey (Stats SA, 2014) where only $7.8 \%$ of participants considered their drinking water to be unsafe. Consistent with previous research (Doria, 2010; Wright et al., 2012), participants based their perceptions of water quality on organoleptic properties such as clarity, odour and taste. More than two-thirds of Bophirima residents felt that the water sources in their community are being managed correctly. However, only about half of those living in Dr KK district felt this way, which is consistent with findings from the 2014 General Household Survey (Stats SA, 2014) where only $43.3 \%$ of NWP residents rated municipal water quality as good. Additional analysis revealed that concerns about water management in the Dr KK district were mostly limited to those residing in Setshing, suggesting that local government in the region might need to address either water management practices, or public perceptions about water management in the region.

Compared to the 2014 national average of $85.9 \%$ (Stats SA, 2014), roughly four-fifths of Bophirima residents and two-thirds of Dr KK residents obtained water from municipal sources, most often via taps inside their homes. However, in Kgakala and Setshing, less than half of participants had access to municipal water sources. In the absence of the latter, windmill-driven boreholes and rainwater also constituted significant sources of water. Water from natural sources such as dams and rivers was rarely used, except in Tigane, where water was commonly obtained from such sources. As such, residents from this community might carry a greater risk of exposure to waterborne contaminants and disease agents. A need therefore exists to improve access to municipal water in Kgakala, Setshing and Tigane. Furthermore, initiatives aimed at informing Tigane residents of the dangers associated with the use of natural sources of water, and providing instruction in the safe utilization of such water sources might serve as pre-emptive strategies against exposure to potential water-based contaminants and disease agents in this community.

As far as uses of water are concerned, virtually all participants used water for washing, cooking, personal hygiene, flushing toilets, washing clothes, and watering gardens and subsistence crops.

A variety of spiritual and cultural beliefs and uses of water were also identified, which included using water as means to establish contact with ancestors, to enable spiritual cleansing before and after funerals and church services, to drive out evil spirits, initiate traditional healers, and to make traditional beer.

In relation to water storage, it was found that the majority of participants stored water inside the home, most typically inside a fridge. However, large numbers of residents (especially in Setshing, Kgakala, and Lebaleng) stored their water in containers outside the home. Future research could investigate the hygienic and safety-related aspects of this practice in order to determine if any health risks are posed by this method of water storage.

As far as demographic characteristics are concerned, comparative analysis of the findings revealed that income levels, age, and gender appear to play a negligible role in the water-related perceptions and behaviours of the participants. These findings are consistent with those of Wright et al. (2012) who found that demographic characteristics and socio-economic status

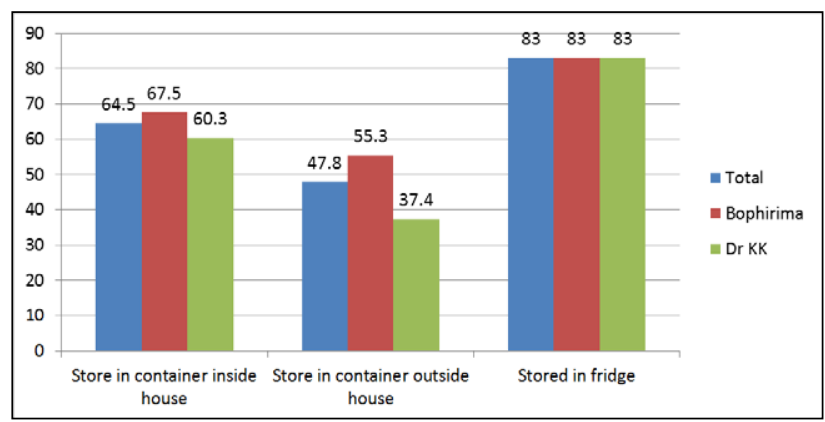

Figure 7

Water storage in communities in the Dr KK and Bophirima districts of the North West Province

of participants were unrelated to their perception of drinking water quality.

The study served to provide a descriptive overview of a variety of aspects related to perceptions, sources and uses of water in the NWP of South Africa. The results of the study have direct practical implications for water management and for the development and implementation of water-related interventions and projects within the NWP.

On a broader level, the findings of the study indicate that interactions with water are complex and driven by far more than basic physiological and other human needs. A host of beliefs and perceptions are often associated with water, which directly impact the manner in which this scarce resource is utilized. Policies aimed at water management and community well-being, especially in communities where traditional beliefs and practices still prevail, should therefore take such beliefs and practices into account, as effective water management is unlikely to be achieved in the absence of such contextually-sensitive understanding of the perceptions, beliefs and uses of water in such communities.

\section{ACKNOWLEDGMENTS}

The authors would like to thank the Water Research Commission (WRC) of South Africa (Contract number K5/1966) for the financial support of this study. Views expressed are those of the authors and not those of the WRC.

\section{AUTHOR CONTRIBUTIONS}

All three authors contributed to the research equally.

\section{CONFLICTS OF INTEREST}

The authors have no conflicts of interest to report.

\section{REFERENCES}

ADAMS M, BERKOFF J and DALEY E (2006) Land-water interactions: Opportunities and threats to water entitlements of the poor in Africa for productive use. Human Development Report Office Occasional Paper 20/2006. UNDP, New York.

ANDERSON BA, ROMANI JH, PHILLIPS H, WENTZEL $M$ and TLABELA K (2007) Exploring environmental perceptions, behaviours and awareness: water and water pollution in South Africa. Popul. Environ. 28 (3) 133-161. http://dx.doi.org/10.1007/ s11111-007-0038-5

BRACE N, KEMP R and SNELGAR R (2012) SPSS for Psychologists $\left(5^{\text {th }}\right.$ edn). Palgrave Macmillan, Hampshire, UK. 
CASCHETTO M, BARBIERI M, GALASSI DMP, MASTRORILLO L, RUSI S, STOCH F, CIOCCIO AD and PETITTA M (2014) Environ. Earth Sci. 71 1791-1807. http://dx.doi.org/10.1007/ s12665-013-2584-8

CRESWELL J (2008) Qualitative Inquiry and Research Design: Choosing Among Five Traditions. Sage, Thousand Oaks, CA.

DORIA M (2010) Factors influencing public perception of drinking water. Water Polic. 12 1-19. http://dx.doi.org/10.2166/wp.2009.05

DWAF (DEPARTMENT OF WATER AFFAIRS AND FORESTRY, SOUTH AFRICA) (1994) URL: https://www.dwa.gov.za/Documents/ Policies/WSSP.pdf (Accessed 3 June 2016)

DWAF (DEPARTMENT OF WATER AFFAIRS AND FORESTRY, SOUTH AFRICA) (1996) National Sanitation Policy. URL: https:// www.dwa.gov.za/Documents/Policies/National\%20Sanitation\%20 Policy.pdf (Accessed 3 June 2016).

FIELD A (2005) Discovering Statistics Using SPSS. SAGE Publications, London.

GAOGANEDIWE B (2010) Diarrhoea outbreak in Bloemhof stabilising. URL: http://www.info.gov.za/speeches/2006/06022209151002.html (Accessed 20 March 2016).

GCIS (2010) Diarrhoea and typhoid outbreak in Delmas under control. URL: http://www.sabcenews.com/south_africa/ health/0,22172,113421,00.html (Accessed 20 March 2016).

HARVEY PA and REED RA (2006) Community-managed water supplies in Africa: Sustainable or dispensable? Community Dev. J. 42 (3) 365-378.

HU D, YAN JS, LIU TX, CHEN GW, YUAN SJ and WANG RS (2004) An integrated analysis of sustainable human-water interactions in wetland ecosystems of Taihu Lake Basin, east China. Dev. Ecosystems 1 183-220. http://dx.doi.org/10.1016/b978-044451691-6/50015-6

LANDMAN WA (2012) Tswaing is trying to convince Sannieshof that the moon is made of green cheese. http://www.ethicsa.org/index. php?page=articlestswaing (Accessed 20 March 2016).

PARIS K (2011) Improving the information base to better guide water resource management decision making. Water Resour. Dev. 27 (4) 625-632.

PLANO CLARK VL and CRESWELL JW (2007) Designing and Conducting Mixed-Methods Research. Sage, Thousand Oaks, CA.

RSA (REPUBLIC OF SOUTH AFRICA) (1996) Constitution of the Republic of South Africa. URL: file://C:/Users/12894451/ Downloads/Constitution\%20of\%20the\%20Republic\%20of\%20 South\%20Africa.pdf (Accessed 3 June 2016).
RUSSELL S and FIELDING K (2010) Water demand management research: A psychological perspective. Water Resour. Res. 46 (5) 1-12. http://dx.doi.org/10.1029/2009wr008408

STATS SA (STATISTICS SOUTH AFRICA) (2014) General household survey. URL: http://www.statssa.gov.za/publications/P0318/ P03182014.pdf (Accessed 20 March 2016).

SUN G and SEGURA C (2013) Interactions of forest, climate, water resources, and humans in a changing environment: Research needs. Brit. J. Environ. Clim. Change 3 (2) 119-126. http://dx.doi. org/10.9734/BJECC/2013/6212

TEMPELHOFF JWN (2009) Civil society and sanitation hydropolitics: A case study of South Africa's Vaal River Barrage. Phys. Chem. Earth 34 164-175. http://dx.doi.org/10.1016/j.pce.2008.06.006

VAN VUUREN L (2013) Poor and angry - research grapples with reasons behind social protests: water and society. The Water Wheel 6 14-16.

WEISKEL PK, VOGEL RM, STEEVES PA, ZARRIELLO PJ and DESIMONE LA (2007) Water use regimes: Characterizing direct human interaction with hydrologic systems. Water Resour. Res. 43 1-11. http://dx.doi.org/10.1029/2006WR005062

WILLIS RM, STEWARTB RA, PANUWATWANICH K, WILLIAMS PR and HOLLINGSWORTH LA (2011) Quantifying the influence of environmental and water conservation attitudes on household end use water consumption. J. Environ. Manage. 92 (8) 1996-2009. http:// dx.doi.org/10.1016/j.jenvman.2011.03.023

WRIGHT JA, YANG H, RIVETT U and GUNDRY W (2012) Public perception of drinking water safety in South Africa 2002-2009: a repeated cross-sectional study. BMC Public Health 12 556-565. http://dx.doi.org/10.1186/1471-2458-12-556

ZAMXAKA M, PIRONCHEVA G and MUYIMA NYO (2004) Microbiological and physic chemical assessment of the quality of domestic water sources in selected rural communities of the Eastern Cape Province, South Africa. Water SA 30 333-340.

ZHANG HH and BROWN DF (2005) Understanding urban residential water use in Beijing and Tianjin, China. Habitat Int. 29 (3) 469-491. http://dx.doi.org/10.1016/j.habitatint.2004.04.002 